\title{
CRESCIMENTO RADIAL DO FUNGO Metarhizium anisopliae ATRAVÉS DE ANÁLISE DE IMAGEM
}

\author{
E.H.S.OLIVEIRA ${ }^{1 *}$, G.R.JESUS ${ }^{1}$, L.M.DUARTE ${ }^{1}$ e L.M.GRAJALES $^{1 * *}$ \\ ${ }^{1}$ Universidade Federal do Tocantins, Departamento de Engenharia de Alimentos \\ E-mail para contato: *eduhenrique@outlook.com e**grajales@uft.edu.br
}

\begin{abstract}
RESUMO - Atualmente, muitos fungos são produzidos para serem aplicados na indústria, principalmente, na indústria agrícola, já que constituem uma alternativa compatível com o ambiente. Um claro exemplo é o uso do fungo entomopatogênico Metarhizium anisopliae empregado como pesticida biológico para controlar pragas como a Mahanarva posticata, a cigarrinha-da- folha que se dá nos cultivos de cana-de- açúcar, gafanhotos, besouro do grão do trigo, carrapatos de impacto na pecuária, broca cana e outros insetos da ordem lepidópteros. $\mathrm{O}$ estudo do crescimento deste microrganismo aliado à análise de outras variáveis como temperatura, $\mathrm{pH}$ e meios de cultivo, permite ajustar modelos matemáticos visando sua produção em uma escala maior. Por este motivo, o presente trabalho teve como principal objetivo determinar o crescimento radial do fungo Metarhizium anisopliae através da técnica de análise de imagem. Para atingir o objetivo, o fungo foi cultivado em meio BDA e fotografado em intervalos definidos de tempo. Posteriormente, as imagens foram digitalizadas e as áreas de crescimento contabilizadas pelo software "Image pro plus", onde as informações obtidas foram ajustadas a um modelo matemático que permitirá predizer a taxa de crescimento do fungo.
\end{abstract}

\section{INTRODUÇÃO}

Com a grande expansão das atividades agrícolas, muitas pragas que destroem as plantações estão se desenvolvendo, e com o intuito de evitar a perda, os agricultores acabam optando pela utilização de agrotóxicos, o que é muito prejudicial para a saúde humana e após o processamento do alimento não é possível retirar todos os resíduos com facilidade (Moura, 2007). A fim de tornar as lavouras mais produtivas, ou seja, com pouca perda devido ao ataque de insetos e fazer com que o alimento produzido não cause danos à saúde humana, a utilização de meios de controle biológico vem crescendo a cada vez mais (Messias, 1989) e com as vantagens de ser um meio mais barato é muito mais eficaz (Pomella e Ribeiro, 2009). Tal é o caso do fungo entomopatogênico Metarhizium anisopliae que ataca gafanhotos, cigarrinhas de cana-de-açúcar e besouros do grão de trigo (Grajales, 2010). O fungo invade os insetos penetrando as suas cutículas ou "pele", uma vez dentro eles se multiplicam rapidamente causando a destruição da praga e ocasionalmente toxinas (Gravena, 2000). Eles emergem, frequentemente, do corpo dos insetos para produzir os esporos, que quando esparramados pelo vento, chuva ou contato com outros insetos espalham a infecção pela área (Gravena, 2000). 
Devido à importância do crescimento microbiano para aplicação em lavouras como pesticidas biológicos, alguns autores tem feito seguimento desse crescimento através de modelos matemáticos que permitem predizer o seu comportamento, Vieira (2000) por exemplo, utilizou um modelo matemático para bovino a pasto, onde fazia a simulação da dinâmica de nutrientes no trato gastrointestinal e com isso observava a atividade microbiana em cada animal. Outro pesquisador que utilizou modelos matemáticos para predizer a taxa de crescimento microbiano foi Sarmento (2006), onde fez a modelagem do crescimento microbiano em mortadela e salsicha defumada em processos isotérmicos e não isotérmicos. Da Silva (2004) fez a análise da cinética de crescimento do fungo Eremothecium ashbyii onde utilizou o método Kono que a partir deste método se é capaz de estimar a produtividade celular.

Com o avanço da tecnologia, novas técnicas de análise vêm surgindo. O Método de Análise de imagem é um método inovador e a partir dele se é capaz de descobrir várias características do observado, como a quantidade colônias formadas por um microrganismo e a dimensão de seu tamanho de ocupação no meio de cultura, dentre outras (Gomes, 2008). Esta técnica vem se destacando muito na sociedade de pesquisadores, visto que é rápido, confiável, reduz os possíveis erros causados pela manipulação das amostras e permite analisar vários objetos simultaneamente (Balaban, 2008). Assim, o objetivo principal deste trabalho é analisar através da técnica de análise de imagem, o crescimento do fungo Metarhizium anisopliae ao longo do tempo.

\section{MATERIAIS E MÉTODOS}

\subsection{Materiais}

O fungo entomopatogênico Metarhirzium anisopliae cepa ICBC 425 foi utilizado sob a forma de esporos puros em pó, armazenados à temperatura de $-4{ }^{\circ} \mathrm{C}$. A cepa foi adquirida no laboratório Biocontrol, localizada na cidade de Sertãozinho-SP.

\subsection{Metodologia}

Quinze mililitros de meio de cultura BDA (Batata-Dextrose-Ágar) dispostos em placas de petri de $11 \mathrm{~cm}$ de diâmetro foram esterilizados a $121^{\circ} \mathrm{C}$ por 20 minutos. Após, o meio solidificar à temperatura ambiente, o fungo foi cultivado com unicamente uma pincelada de esporos no centro geométrico das placas de petri, isto em câmara de fluxo laminar marca Marconi modelo MA1550/1. Imediatamente, o conjunto foi colocado em câmara climatizada BOD marca Adamo à temperatura de $28{ }^{\circ} \mathrm{C} \pm 1{ }^{\circ} \mathrm{C}$ durante 07 dias. Periodicamente, as placas de petri com o fungo foram retiradas da BOD para serem fotografadas e posteriormente analisadas mediante o software "Image pro plus (Media Cibernetics)" na versão gratuita.

O sistema completo para as fotografias consistiu em um suporte de isopor quadrado de $17 \mathrm{~cm}$ de lado e $17 \mathrm{~cm}$ de altura. $O$ suporte contou com uma perfuração redonda de $5 \mathrm{~cm}$ de diâmetro, conforme apresentado no esquema da Figura 1, para localizar a lente da câmera fotográfica Sony modelo DSC-W230 de 12.1 Mega Pixels. As condições de iluminação foram sempre controladas para garantir a padronização das fotos 
Figura 1- Suporte para fotografia.

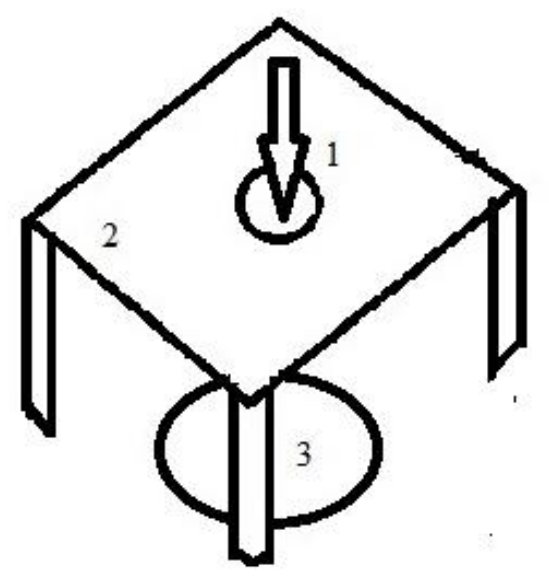

1- Perfuração para lente da câmera;

2- Suporte da câmera;

3- Placa de Petri.

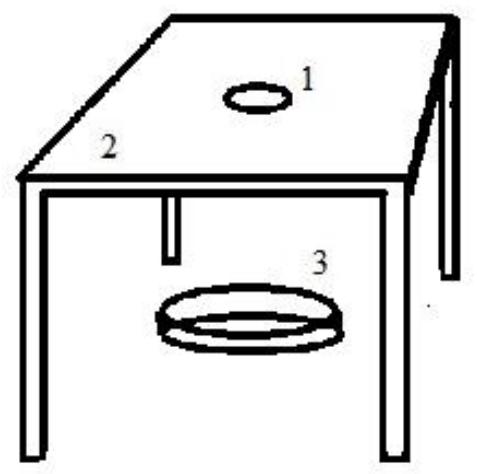

A superfície das placas de petri foram fotografadas, as imagens digitalizadas e em seguida contabilizada a área, o raio e o diâmetro de crescimento do fungo mediante o software Image ProPlus, conforme esquema da Figura 2. Os valores referentes ao raio, diâmetro e área foram todos disponibilizados pelo software, onde os valores se encontravam em pixels e após uma simples conversão de unidades foi transformado para centímetros ou centímetros quadrados.

Figura 2- Layout da análise de imagem

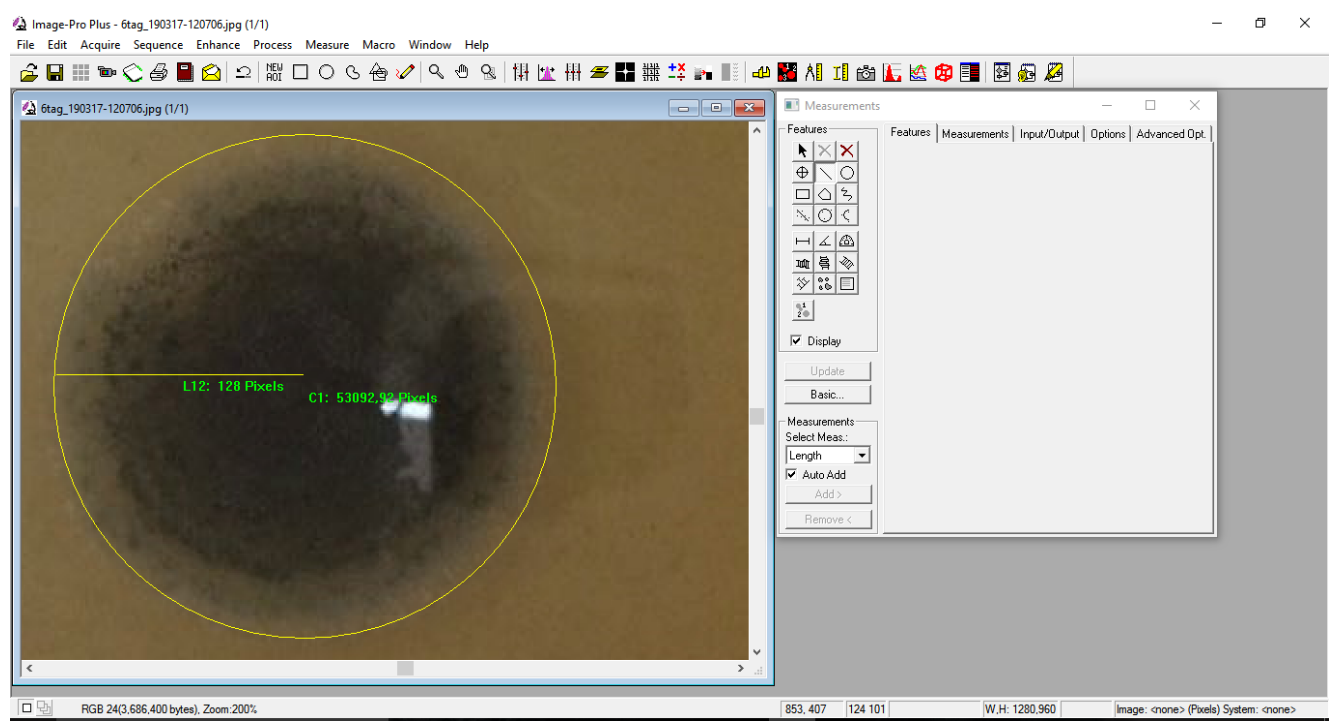

\section{RESULTADOS E DISCUSSÕES}

Com as informações de área e raio obtidas foram realizados gráficos da sua variação em função do tempo para posteriormente, analisar cada estágio da curva de crescimento, ou seja, detectar o momento em que o fungo inicia e termina a fase lag, exponencial, estacionária 
e de morte (Bastos, 2010). As Figuras 3 e 4 mostram a variação do raio e de área em função do tempo.

Pode-se observar que até o tempo de 24 horas após o processo de inoculação, o fungo ainda estava se adaptando ao meio, permanecendo na fase lag. Segundo Dickinson \& Bottomley (1980) os fungos são capazes de manter-se até encontrar-se em condições favoráveis para retomar seu crescimento, portanto todo esse tempo que não houve crescimento micelial do fungo foi devido ao processo de adaptação. A partir das 36 horas se inicia a curva de crescimento exponencial, a qual é a de maior interesse nesse estudo já que visa analisar o seu período de maior eficiência, com o início do crescimento micelial percebese que com 12 horas do início desse crescimento, o fungo obteve um crescimento praticamente dobrado e a cada 12 horas percebeu-se esse comportamento. De acordo com Bastos (2010) após o final da fase de adaptação os microrganismos começam a se multiplicar rapidamente, dobrando seu número em espaços regulares de tempo, conforme foi observado.

Observe-se que no momento de 108 horas o fungo apresentou uma pequena diminuição de seu crescimento e após 12 horas desse decaimento de velocidade houve um novo aumento de velocidade, retomando o padrão de dobramento de tamanho. Essa pequena modificação na estrutura de crescimento do fungo de acordo com Nielsen (2002) e Dutta (2008) pode ter se dado pelo esgotamento de um ou mais nutrientes ou por algum pequeno acúmulo de subproduto tóxico para o seu crescimento, pois com o ambiente em acelerada mudança acontece de o microrganismo muitas vezes ter o crescimento desequilibrado.

Figura 3 - Crescimento radial do fungo em função do tempo.

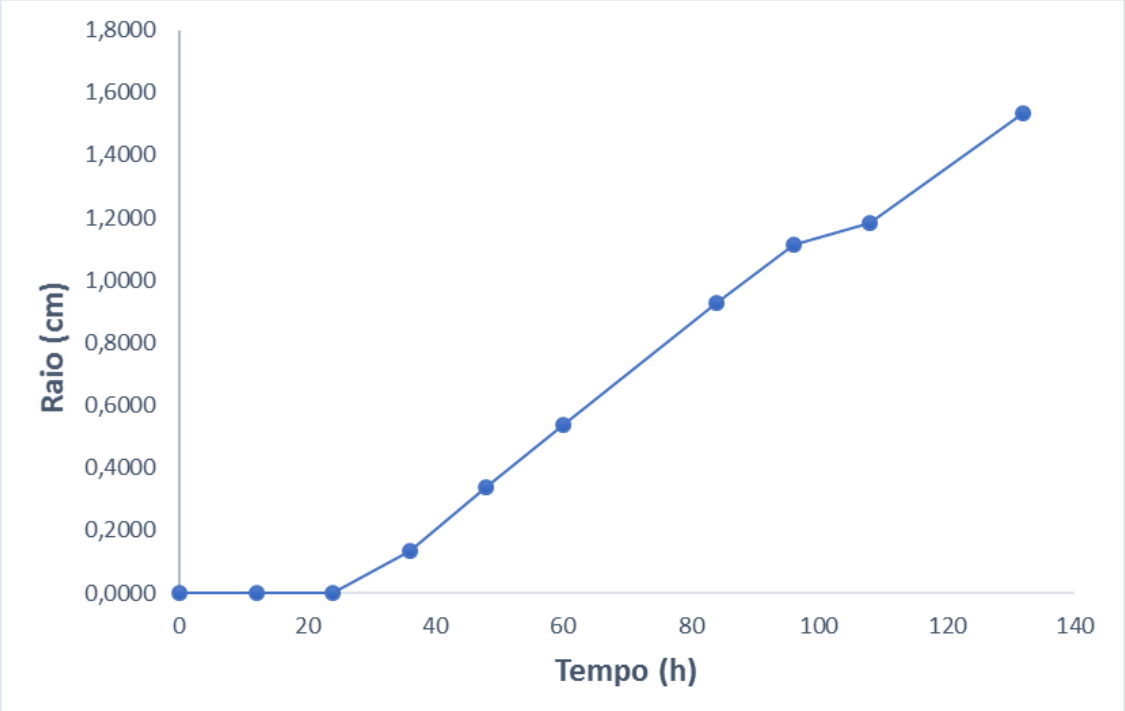


Figura 4 - Aumento de área do fungo em função do tempo.

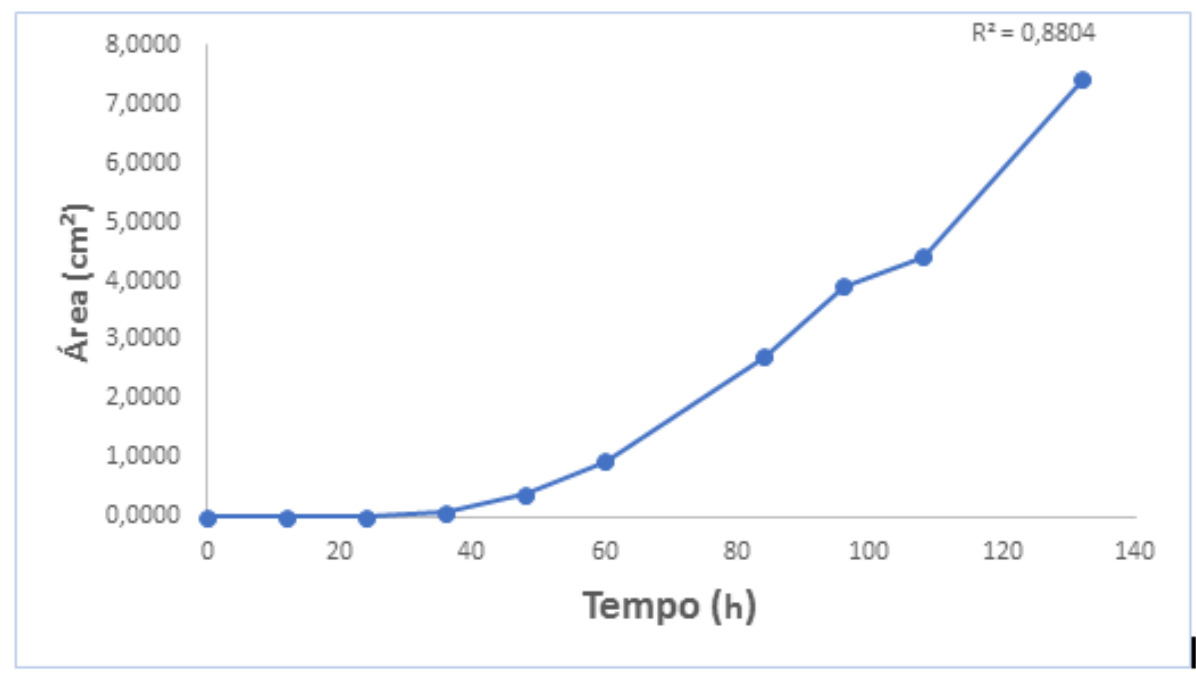

Pretende-se continuar avaliando o crescimento do M. anisopliae após 130 horas de experimentos, com o objetivo de determinar a fase estacionária e fase de morte do microrganismo, podendo assim gerar modelos matemáticos completos que permitam determinar a cinética de crescimento do mesmo.

\section{CONCLUSÃO}

De acordo os objetivos esperados, pode-se perceber que os mesmos foram alcançados com extremo êxito, verificando que em um período de sete dias é o período no qual o fungo melhor se desenvolve e a partir destes resultados conclui-se que sua velocidade de crescimento a cada 12 horas nesse período de sete dias de crescimento manteve um padrão de praticamente dobrar sua velocidade de crescimento radial.

\section{REFERENCIAS}

BALABAN, M. O. Quantifying Nonhomogeneous Colors in Agricultural Materials Part I: Method Development. Journal of Food Science, Chicago, v. 73, n. 9, p. 431 - 437, 2008.

BARBOSA, B. C. Controle biológico. Disponível em: < http://www.infoescola.com/ecologia/controle-biologico/> Acesso em 20 de Março de 2017

BASTOS, G. R. Tecnologia das fermentações: Fundamentos de bioprocessos. Coleção UAB-UFSCar, p. 92-93, 2010.

BUENO, V. H. P.; V. L. , J. C.. Controle biologico de pragas em cultivos protegidos. Ciência \& Ambiente, v. 43, p. 211-230, 2011 
DA SILVA, R. S. F. Cinética de crescimento de fungos: I. Modelo matemático para o Eremothecium Ashbyik. Semina: Ciências Exatas e Tecnológicas, v. 2, n. 8, p. 199-201, 2004.

DE MOURA, R. M. Agrotóxicos: Heróis ou vilões? A face da questão que todos devem saber. Anais da Academia Pernambucana de Ciência Agronômica, v. 4, p. 23-49, 2014.

DUTTA, R. Fundamentals of biochemical engineering. v.1, p. 106-140, 2008.

GOMES, M. I. S. Monitorização do crescimento de um biofilme fotossintético por análise de imagem. 2008. Tese de Doutorado. FCT-UNL.

GRAJALES, L. M. Avaliação de um biorreator rotativo para fermentação em estado sólido. 2010.

GRAVENA, S. Os fungos no controle de insetos, 2000. Disponível em: < http://www.grupocultivar.com.br/artigos/os-fungos-no-controle-de-insetos/> Acesso_em 19 de Março de 2017.

GRAVENA, S. Controle biológico no manejo integrado de pragas. Pesquisa Agropecuária Brasileira, v. 27, n. 13, p. 281-299, 1992.

MESSIAS, C. L. Fungos, sua utilização para controle de insetos de importância médica e agrícola. Memórias do Instituto Oswaldo Cruz, v. 84, p. 57-59, 1989.

NIELSEN, J. H.; VILLADSEN, J.; LIDÉN, G. Bioreaction Engineering Principles. V.2, p.10, 2002.

POMELlA, A. W. V.; RIBEIRO, R. T. S. Controle biológico com Trichoderma em grandes culturas-uma visão empresarial. Biocontrole de Doenças de Plantas, p. 239, 2009.

REGINA, M. Cinética do crescimento miceliano de Lentinula edodes (Berk.) Pegler em bagaço de cana-de-açúcar e serragem de eucalipto. 2001.

SARMENTO, C. M. P. Modelagem do crescimento microbiano e avaliação sensorial no estudo da vida de prateleira da mortadela e da linguiça defumada em armazenamento isotérmico e não isotérmico. 2006.

VIEIRA, R. A. M.; PEREIRA, J. C.; MALAFAIA, P. A. M.; QUEIROZ, A. C.; JORDÃO, C. P.; GONÇALVES, A. L. Simulação da dinâmica de nutrientes no trato gastrintestinal: aplicação e validação de um modelo matemático para bovinos a pasto. Revista Brasileira de Zootecnia, v. 29, n. 3, p. 898-909, 2000. 